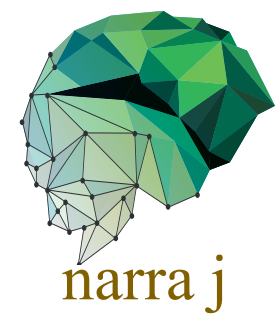

Original Article

\title{
Impact of economic disruptions and disease experiences on COVID-19 vaccination uptake in Asia: A study in Malaysia
}

\author{
Abram L. Wagner1* ${ }^{*}$, Yogambigai Rajamoorthy² and Niazlin M. Taib3 \\ ${ }^{1}$ Department of Epidemiology, School of Public Health, University of Michigan, Ann Arbor, MI, USA; ${ }^{2}$ Department of \\ Economics, Faculty of Accountancy and Management, Universiti Tunku Abdul Rahman, Sungai Long Campus, Cheras, \\ Selangor, Malaysia; 3Department of Medical Microbiology and Parasitology, Faculty of Medicine and Health Science, \\ Universiti Putra Malaysia, Serdang, Selangor, Malaysia
}

*Corresponding author: awag@umich.edu

\begin{abstract}
During the coronavirus disease 2019 (COVID-19) pandemic, individuals have had a variety of experiences with the disease and economic disruptions in Asia. We assessed how these experiences could impact COVID-19 vaccination intent and uptake in one of the Asian country, Malaysia. Two opt-in internet-based cross-sectional samples were collected: a March wave (26 March - 7 April 2021) and a June wave (22 June - 10 July 2021). Individuals were asked about their vaccination status, their employment status, and their experience with COVID-19 cases. The impact of economic disruptions and experiences with COVID-19 on COVID-19 vaccination was assessed through a multivariable, multinomial logistic regression model. Among 1,493 participants (735 in March and 758 in June wave), 26\% were already vaccinated, $57 \%$ planned to vaccinate, and $17 \%$ had no plan to vaccinate. The number who had lost a job or earned less because of the pandemic was $30 \%$ in March and $36 \%$ in June. Across both waves, $5 \%-6 \%$ had a personal, very serious experience of COVID-19, $13 \%-16 \%$ knew of a family member or friend with a very serious experience of COVID-19, and $43 \%-61 \%$ knew of a very serious COVID-19 case through media. Notably, compared to those who worked the same amount throughout the pandemic, those who lost their job had lower odds of already being vaccinated (OR: 0.37 ; 95\%CI: $0.23,0.59$ ), but similar odds of planning to become vaccinated. Personal, family/friend, and media experiences were also all related to increased odds of planning to vaccinated or being already vaccinated. The COVID-19 pandemic has led to large disruptions in people's lives. People's experiences during the pandemic impact their likelihood of being vaccinated or planning to vaccinate against COVID-19. Equitable allocation of COVID-19 vaccines will require outreach to groups with less stable employment and can leverage people's experiences with disease during the pandemic.
\end{abstract}

Keywords: SARS-CoV-2, cross-sectional studies, employment, COVID-19, COVID-19 vaccines

\section{Introduction}

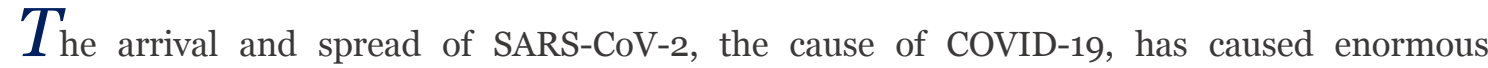
disruptions to everyday life in Asia region $[1,2]$ and has resulted in the deaths of over 7,500 in Malaysia, as of 22 July 2021 [3]. A Movement Control Order related to the restriction of movement throughout the nation was implemented to control the spread of the virus. 
This order led to uncertainty in the agriculture, industry and service sectors [4]. Within Malaysia, there have also been substantial job losses related to the pandemic. Moreover, a reduction in economic output and increase in unemployment rate caused the Malaysian economy to shrink due to COVID -19 [5].

Widespread uptake of COVID-19 vaccinations, alongside adherence to non-pharmaceutical interventions, will be important to global control of COVID-19 and limiting the emergence and spread of variants. In Malaysia, vaccination programs started on 24 February 2021, but as of 21 July 2021, only $33 \%$ had been vaccinated ( $15 \%$ fully vaccinated and the rest partially vaccinated) [6].

Yet, the emergence of anti-vaccine movements and vaccine hesitancy could still impact the roll-out of the COVID-19 vaccine in Malaysia and other locations. It is important to assess the barriers or promoters influence an individual to get vaccinated. Given the large disruptions to everyday life over the past year, it will also be essential to document how the pandemic has affected individuals' willingness to be resilient and to adopt pro-public health behaviors, like vaccination. In this study, we estimate vaccination uptake, along with experiences with COVID19 and economic disruptions like job losses, in Malaysia. We also characterize how these epidemiological and economic experiences affect willingness to receive a COVID-19 vaccine.

\section{Methods}

\section{Study population}

An opt-in internet-based sample was used, whereby a survey research firm sent out a link of the questionnaire to a list of panelists that they obtained from social media and other online advertisements. This study consisted two waves of data collection: a March wave (26 March -7 April 2021) and a June wave (22 June - 10 July 2021). Eligible participants included adults at least 18 years of age who were resident in Malaysia. The sample size calculation was based on a desired sample size of 80o. This number was based on a desire to estimate precise proportions (with a conservative estimate of $50 \%$ and a margin of error of $4 \%$ ), using an alpha of 0.05 and a power of $80 \%$.

To create a representative sample, age and gender quotas were used. Weights were created using a raking procedure [7] to reflect the age, gender, and regional distribution.

\section{Outcome variable}

The main outcome of this analysis was vaccination status. Individuals were asked "Have you received a COVID-19 vaccine?" If they answered "No", they were asked "How much do you agree or disagree with this statement? I plan to get a COVID-19 vaccine." Responses were on a 5-point Likert scale from "Strongly Disagree" to "Strongly Agree". From these two responses we categorized individuals into three categories: those already vaccinated, those planning to vaccinate (who answered "Agree" or "Strongly agree" to the planning question), and those not planning to vaccinate (those who answered "Neutral", "Disagree", or "Strongly disagree" to the planning question).

\section{Independent variables}

The independent variables consisted two groups of experiences: economic disruptions and experiences with COVID-19 disease. For economic disruption, we asked a series of questions about employment status. We asked how and if they were employed. Those who responded that they were out of work for one year or more, a homemaker, a student, retired, or unable to work were categorized as "not working". Those who were employed for wages, self-employed, or out of work for less than one year were subsequently asked "Has how much you work changed as a result of the coronavirus outbreak?" and "Has how much you are paid changed as a result of the coronavirus outbreak?" Those who responded that they were let go from their job or retrenched, or that they were getting paid less were categorized separately from those who maintained their current jobs with similar amount of payment despite working from home or working on alternate days. 
Disease experiences were assessed across three dimensions. We first asked if the individual participants had been infected with coronavirus, if they knew close friends or family members who had been infected, and if they had seen or read about individuals infected with coronavirus in social media or on TV. If they answered yes to any of these, they were then asked what they perceived the course of illness to be, with the options very serious, somewhat serious, and not very serious. From these questions we were able to create three variables: "Personal experience with COVID-19", "Friends or family members' experience with COVID-19", and "Media experience of a COVID-19 case". For each variable, the options were "Very serious experience", "Not very serious experience", and "No experience".

Gender, age, race, education, and family income were control variables included in the analysis.

\section{Statistical analysis}

We tested for the significance of differences in vaccination status across the independent variables using a Rao-Scott chi-square test that incorporated weights. Subsequently, all independent variables were entered into a multivariable, multinomial logistic regression model that output odds ratios (ORs) and 95\% confidence intervals (CIs). Analyses were conducted in SAS version 9.4 (SAS Institute, Cary, NC, USA). Significance was assessed at an alpha level of 0.05 .

\section{Results}

In total, 957 participants started the March survey, and 1,258 the June survey, but only 803 and 840, respectively, agreed to the informed consent. After removing individuals who completed the survey too quickly - in under 3 minutes, and those who did not reach the end of the questionnaire, we were left with 749 individuals who completed the survey in the March wave, and 779 in the June wave. Nine individuals with missing economic data, and 27 individuals in the "other" race category were excluded leaving a final sample size across both waves of 1,493. Details of the study sample are presented in Table 1. There were large economic disruptions to individuals over the course of the pandemic. Although 23\%-26\% had not worked before, 30\%$36 \%$ had lost their job or earned less currently versus before the pandemic. Among those who had been employed at the start of the pandemic, $5 \%$ lost their jobs, and, among those still working, $43 \%$ earn less compared to before the pandemic.

People's experiences with the pandemic also varied. Over 90\% had not been diagnosed with COVID-19, but among those who did, many had a very serious course of illness (5\%-6\% of the entire sample). Around one-third of the sample knew a close friend or family member who had had COVID-19, and a large proportion of these illnesses were considered very serious (13\%$16 \%$ of the entire sample). Most had had an experience viewing or reading about a COVID-19 case in the media: with $43 \%$ in the March wave, and $61 \%$ in the June wave indicating that they remembered a very serious case of COVID-19 from the media.

Overall, 26\% of the population had already been vaccinated, and a majority of the rest (57\% of the total) planned to be vaccinated (Table 2). Only $17 \%$ had no plans to receive a COVID-19 vaccine. These numbers changed over time - with $16 \%$ already vaccinated in the March wave, and $36 \%$ in the June wave. The proportion with no plans to vaccinate also decreased, from $23 \%$ to $11 \%(\mathrm{P}<0.001)$. Economic experiences during the pandemic were also influential. Those with a steady work schedule were more likely to be vaccinated (33\%) than those who were not working (20\%), or who had lost their job or earned less as a result of the pandemic (22\%, $\mathrm{P}=0.047$ ). No intent to vaccinate was relatively low among those with a steady job (13\%) but also higher in those who did not work (24\%), or who lost their job or earned less because of the pandemic (18\%). Experiences with disease also significantly related to vaccination status. Those with a serious case of illness had substantially higher vaccination coverage (74\%) compared to those with no such experience $(23 \%, \mathrm{P}<0.001)$. Those knowing friends or family members with a very serious course of COVID-19 also had higher rates of vaccination ( $47 \%$ vs. $33 \%$ whose friends and family had a not very serious case of COVID-19, and 19\% among those with no such experience, $\mathrm{p}<0.001$ ). In a similar trend, having heard of or seen COVID-19 cases which were 
very serious in the media also was associated with higher vaccination coverage (32\% vs. 20\% with no experience), and lower non-intentions (12\% vs. $31 \%$ among those with no such experience).

Table 1. Demographic distribution of study participants in Malaysia by survey wave

\begin{tabular}{|c|c|c|}
\hline \multirow[t]{2}{*}{ Variable } & \multicolumn{2}{|l|}{ Wave } \\
\hline & $\begin{array}{l}\text { 26 March - } 7 \text { April } \\
\text { n (\%) }\end{array}$ & $\begin{array}{l}\text { 22 June - 10 July } \\
\mathrm{n}(\%)\end{array}$ \\
\hline Total & 735 & 758 \\
\hline \multicolumn{3}{|l|}{ Gender } \\
\hline Female & $361(47)$ & $369(48)$ \\
\hline Male & $374(53)$ & $389(52)$ \\
\hline \multicolumn{3}{|l|}{ Age } \\
\hline 24 year or younger & $151(19)$ & $148(18)$ \\
\hline 25-34 year & $199(26)$ & $199(24)$ \\
\hline $35-44$ year & $191(24)$ & $190(23)$ \\
\hline 45-54 year & $167(20)$ & $172(19)$ \\
\hline 55 year or older & $27(12)$ & $49(17)$ \\
\hline \multicolumn{3}{|l|}{ Race } \\
\hline Malay & $529(72)$ & $580(76)$ \\
\hline Chinese & $175(24)$ & $155(21)$ \\
\hline Indian & $31(4)$ & $23(3)$ \\
\hline \multicolumn{3}{|l|}{ Education } \\
\hline High school or less & $192(30)$ & $288(41)$ \\
\hline Some college & $543(70)$ & $470(59)$ \\
\hline \multicolumn{3}{|l|}{ Income (Ringgit Malaysia) } \\
\hline$<3,000$ & $178(27)$ & $263(35)$ \\
\hline$\geq 3,000$ & $557(73)$ & $495(65)$ \\
\hline \multicolumn{3}{|l|}{ Economic disruptions during pandemic } \\
\hline Did not and does not work & $151(23)$ & $184(26)$ \\
\hline Works same amount & $367(47)$ & $298(37)$ \\
\hline Lost job or earns less because of pandemic & $217(30)$ & $276(36)$ \\
\hline \multicolumn{3}{|l|}{ Personal experience with COVID-19 } \\
\hline No experience & $662(91)$ & $701(93)$ \\
\hline Not very serious & $27(4)$ & $21(3)$ \\
\hline Very serious & $46(6)$ & $36(5)$ \\
\hline \multicolumn{3}{|c|}{ Friends or family members' experience with COVID-19 } \\
\hline No experience & $484(68)$ & $450(61)$ \\
\hline Not very serious & $158(20)$ & $183(24)$ \\
\hline Very serious & $93(13)$ & $125(16)$ \\
\hline \multicolumn{3}{|l|}{ Media experience of a COVID-19 case } \\
\hline No experience & $86(13)$ & $73(9)$ \\
\hline Not very serious & $335(44)$ & $213(30)$ \\
\hline Very serious & $314(43)$ & $472(61)$ \\
\hline
\end{tabular}

In a multivariable, multinomial regression model, economic and disease experiences remained significantly associated with vaccination intent. Notably, compared to those who worked the same amount throughout the pandemic, those who lost their job had lower odds of already being vaccinated (OR: 0.37; 95\%CI: 0.23 , 0.59), but similar odds of planning to become vaccinated (OR: 0.73; 95\%CI: 0.49, 1.10) (Table 3). Those who did not had significantly lower odds of already being vaccinated and planning on being vaccinated. Personal experiences significantly related to vaccination status $(\mathrm{P}<0.001)$. Those with a very serious course of illness were more likely to have already been vaccinated (OR: 3.94; 95\%CI: 1.46, 10.62). However, those with not as serious of a course of illness had reduced odds of planning to become vaccinated (OR: 0.37; 95\%CI: 0.16, 0.87) compared to those with no COVID-19 diagnosis. Knowing friends or family members who had COVID-19, even if not very serious, was associated with higher odds of already being vaccinated, or planning to become vaccinated $(\mathrm{P}<0.001)$. And by media experiences, having some exposure to a COVID-19 case was associated with higher 
odds of already being vaccinated, or planning to, with exposure to a very serious case resulting in even higher odds than exposure to a not very serious case $(\mathrm{P}=0.001)$.

Table 2. Distribution of study participants in Malaysia by COVID-19 vaccination status

\begin{tabular}{|c|c|c|c|c|}
\hline Variable & $\begin{array}{l}\text { No plan to } \\
\text { vaccinate, } \\
\text { n (\%) }\end{array}$ & $\begin{array}{l}\text { Plan to } \\
\text { vaccinate } \\
\text { n (\%) }\end{array}$ & $\begin{array}{l}\text { Already } \\
\text { vaccinated } \\
\mathrm{n}(\%)\end{array}$ & P-value a \\
\hline Total & $243(17)$ & $859(57)$ & $391(26)$ & \\
\hline \multicolumn{5}{|l|}{ Wave } \\
\hline March 2021 & $157(23)$ & $449(61)$ & $129(16)$ & \multirow[t]{2}{*}{$<0.001$} \\
\hline June 2021 & $86(11)$ & $410(53)$ & $262(36)$ & \\
\hline \multicolumn{5}{|l|}{ Gender } \\
\hline Female & $123(17)$ & $445(61)$ & $162(22)$ & \multirow[t]{2}{*}{0.019} \\
\hline Male & $120(17)$ & $414(53)$ & $229(29)$ & \\
\hline \multicolumn{5}{|l|}{ Age } \\
\hline 24 year or younger & $60(21)$ & $180(58)$ & $59(21)$ & \multirow[t]{5}{*}{0.068} \\
\hline 25-34 year & $59(16)$ & $213(54)$ & $126(30)$ & \\
\hline 35-44 year & $65(18)$ & $206(52)$ & $110(30)$ & \\
\hline 45-54 year & $48(15)$ & $221(65)$ & $70(20)$ & \\
\hline 55 year or older & $11(16)$ & $39(57)$ & $26(27)$ & \\
\hline \multicolumn{5}{|l|}{ Race } \\
\hline Malay & $162(16)$ & $626(55)$ & $321(29)$ & \multirow[t]{3}{*}{$<0.001$} \\
\hline Chinese & $70(22)$ & $199(60)$ & $61(18)$ & \\
\hline Indian & $11(16)$ & $34(69)$ & $9(14)$ & \\
\hline Education & $93(19)$ & $259(56)$ & $128(26)$ & \multirow[t]{2}{*}{0.582} \\
\hline High school or less & $150(16)$ & $600(58)$ & $263(26)$ & \\
\hline \multicolumn{5}{|l|}{ Some college } \\
\hline Income (Ringgit Malaysia) & $101(22)$ & $232(54)$ & $108(24)$ & \multirow[t]{2}{*}{0.004} \\
\hline$<3,000$ & $142(15)$ & $627(58)$ & $283(27)$ & \\
\hline$\geq 3,000$ & & & & \\
\hline \multicolumn{5}{|l|}{ Economic disruptions during pandemic } \\
\hline Did not and does not work & $78(24)$ & $196(56)$ & $61(20)$ & \multirow[t]{3}{*}{0.047} \\
\hline Works same amount & $82(13)$ & $367(54)$ & $216(33)$ & \\
\hline Lost job or earns less because of pandemic & $83(18)$ & $296(61)$ & $114(22)$ & \\
\hline \multicolumn{5}{|l|}{ Personal experience with COVID-19 } \\
\hline No experience & $221(17)$ & $825(60)$ & $317(23)$ & \multirow[t]{3}{*}{$<0.001$} \\
\hline Not very serious & $15(33)$ & $20(40)$ & $13(27)$ & \\
\hline Very serious & $7(9)$ & $14(17)$ & $61(74)$ & \\
\hline \multicolumn{5}{|c|}{ Friends or family members' experience with COVID-19 } \\
\hline No experience & $175(20)$ & $578(61)$ & $181(19)$ & \multirow[t]{3}{*}{$<0.001$} \\
\hline Not very serious & $41(11)$ & $193(56)$ & $107(33)$ & \\
\hline Very serious & $27(13)$ & $88(40)$ & $103(47)$ & \\
\hline \multicolumn{5}{|l|}{ Media experience of a COVID-19 case } \\
\hline No experience & $48(31)$ & $78(49)$ & $33(20)$ & \multirow[t]{3}{*}{$<0.001$} \\
\hline Not very serious & $104(20)$ & $340(61)$ & $104(19)$ & \\
\hline Very serious & $91(12)$ & $441(56)$ & $254(32)$ & \\
\hline
\end{tabular}

a Rao-Scott chi-square test

\section{Discussion}

Within two cross-sectional internet-based samples of Malaysian residents, this study examined how economic and epidemiological experiences have affected COVID-19 vaccination intent and actual uptake. High uptake of the vaccine will be critical to mitigate the continued spread of SARS-CoV-2, but limited access to vaccines, combined with apathy or hesitancy in receiving a vaccine, could limit vaccination uptake. Our study found increasing uptake, along with decreased numbers of those not planning to be vaccinated. Experiences with job losses, along with experiences with COVID-19 cases, were all importantly related to vaccination outcomes.

The roll-out of the COVID-19 vaccine has varied widely across countries, but currently Malaysia has the largest share of the population vaccinated in southeast Asia [6]. Nonetheless, its vaccination coverage (around one-third of the population from official sources and our survey) falls behind countries in Europe and North America, like Canada, the United Kingdom, 
and Spain [6]. There is concern that the expense of COVID-19 vaccines may mean that there is less distribution of COVID-19 vaccines in low-income countries [8], which could exacerbate health inequalities and perpetuate the rise of SARS-CoV-2 variants.

Table 3. Multinomial logistic regression of COVID-19 vaccination status among study participants in Malaysia

\begin{tabular}{|c|c|c|c|}
\hline Variable & $\begin{array}{l}\text { Already vaccinated } v s \text {. } \\
\text { no plans to vaccinate } \\
\text { OR }(95 \% \mathrm{CI})\end{array}$ & $\begin{array}{l}\text { Plan to vaccinate } v s . \text { no } \\
\text { plans to vaccinate } \\
\text { OR ( } 95 \% \text { CI) }\end{array}$ & P-value \\
\hline \multicolumn{4}{|c|}{ (9) } \\
\hline June $v s$. March 2021 & $5.63(3.69,8.59)$ & $1.83(1.27,2.64)$ & $<0.001$ \\
\hline \multicolumn{4}{|l|}{ Gender } \\
\hline Female $v s$. male & $0.70(0.47,1.04)$ & $1.16(0.83,1.62)$ & 0.005 \\
\hline \multicolumn{4}{|l|}{ Age } \\
\hline 24 year or younger & Reference & Reference & 0.096 \\
\hline 25-34 year & $1.08(0.59,2.00)$ & $0.81(0.49,1.32)$ & \\
\hline $35-44$ year & $1.03(0.56,1.90)$ & $0.77(0.47,1.26)$ & \\
\hline 45-54 year & $0.79(0.42,1.51)$ & $1.09(0.65,1.82)$ & \\
\hline 55 year or older & $1.36(0.55,3.37)$ & $0.98(0.43,2.23)$ & \\
\hline \multicolumn{4}{|l|}{ Race } \\
\hline Malay & Reference & Reference & 0.008 \\
\hline Chinese & $0.43(0.26,0.71)$ & $0.76(0.50,1.14)$ & \\
\hline Indian & $0.52(0.19,1.43)$ & $1.15(0.54,2.46)$ & \\
\hline \multicolumn{4}{|l|}{ Education } \\
\hline $\begin{array}{c}\text { Some college } v s . \text { less } \\
\text { Income (Ringgit Malavsia) }\end{array}$ & $1.01(0.65,1.57)$ & $1.01(0.69,1.48)$ & 0.998 \\
\hline$<3,000$ vs more & $0.65(0.41,1.03)$ & $0.66(0.45,0.99)$ & 0.101 \\
\hline \multicolumn{4}{|l|}{$\begin{array}{l}\text { Economic disruptions during } \\
\text { pandemic }\end{array}$} \\
\hline Did not and does not work & $0.27(0.15,0.48)$ & $0.51(0.31,0.85)$ & $<0.001$ \\
\hline Works same amount & Reference & Reference & \\
\hline $\begin{array}{l}\text { Lost job or earns less because of } \\
\text { pandemic }\end{array}$ & $0.37(0.23,0.59)$ & $0.73(0.49,1.10)$ & \\
\hline \multicolumn{4}{|l|}{ Personal experience with COVID-19 } \\
\hline No experience & Reference & Reference & $<0.001$ \\
\hline Not very serious & $0.56(0.22,1.43)$ & $0.37(0.16,0.87)$ & \\
\hline Very serious & $3.94(1.46,10.62)$ & $0.44(0.14,1.34)$ & \\
\hline \multicolumn{4}{|l|}{$\begin{array}{l}\text { Friends or family members' } \\
\text { experience with COVID-19 }\end{array}$} \\
\hline No experience & Reference & Reference & $<0.001$ \\
\hline Not very serious & $2.89(1.71,4.90)$ & $1.72(1.08,2.75)$ & \\
\hline Very serious & $1.85(0.97,3.52)$ & $0.92(0.51,1.69)$ & \\
\hline \multicolumn{4}{|l|}{ Media experience of a COVID-19 case } \\
\hline No experience & Reference & Reference & 0.001 \\
\hline Not very serious & $1.22(0.65,2.31)$ & $1.82(1.09,3.06)$ & \\
\hline Very serious & $2.27(1.24,4.16)$ & $2.55(1.54,4.25)$ & \\
\hline
\end{tabular}

Interestingly, our study documents a decline in the number of individuals unwilling to be vaccinated over time (23\% in March to $11 \%$ in June 2021). This is the opposite direction as what we have seen in previous pandemics. There are theoretical reasons why a global pandemic could induce vaccine hesitancy, especially with the rise of misinformation [9]. And in previous pandemics, there has been an increase in vaccine hesitancy over time. For example, negative attitudes towards vaccination generally increased substantially in France from $9.6 \%$ before the $2009 \mathrm{H} 1 \mathrm{~N} 1$ pandemic to $38.2 \%$ after [10]. In Italy, the proportion of the population wanting to receive the $\mathrm{H} 1 \mathrm{~N} 1$ vaccine declined from $36 \%$ to $10 \%$ [11]. Understanding why vaccination intent changes over time will be important.

Our research documented how experiences affect vaccination intent. Changes to employment status and other economic disruptions can be hugely influential for health status. There is a large body of research, for example, documenting how wealth shocks - i.e., large decreases in net wealth - are associated with all-cause mortality [12]. Within this study, we have documented how loss of an employment or reduced wages is associated with decreases in actual vaccination, but not in plans to be vaccinated. In essence, job loss or reduced earnings could reduce an individual's access to vaccination, and they also may be more attuned to the costs - 
financially and temporally - for receiving a vaccine even if it is offered for free. COVID-19 vaccination programs should be aware of how individuals affected negatively throughout the pandemic might have less access to the vaccines, even if they have the desire to be vaccinated.

This study has several limitations. This is a cross-sectional study, so we are not able to exactly assess temporality of events. For instance, individuals could have received the vaccine before losing their job or knowing a friend or family member with a severe case of disease. As an opt-in sample, our study population is also biased towards individuals with internet access. We also have not collected or analyzed more specific reasons why some individuals may be more or less pro-vaccine. Nevertheless, a strength of our study was that we were able to obtain a quota sample, such that we have representation across different age groups. Additionally, we ask about vaccination intent and actual vaccination uptake. In this way we are able to explore access and hesitancy issues at the same time.

\section{Conclusions}

The on-going roll-out of the COVID-19 vaccine in Malaysia faces several challenges. A certain proportion of the population has no desire to be vaccinated, although this number has decreased over time. The COVID-19 pandemic has led to large disruptions in people's lives. People's experiences during the pandemic impact their likelihood of being vaccinated or planning to vaccinate against COVID-19. Equitable allocation of COVID-19 vaccines will require outreach to groups with less stable employment and can leverage people's experiences with disease during the pandemic.

\section{Declarations}

\section{Ethics approval}

The protocol was reviewed and approved by the University of Michigan Health Sciences and Behavioral Sciences Institutional Review Board (\#HUMo0180096) and an ethics review committee at the Universiti Tunku Abdul Rahman (\#U/SERC/107/2020). Participants read an informed consent form and clicked "I agree to participate in the study" before we asked any question.

\section{Acknowledgments}

We appreciate Kaitlyn Akel's help in cleaning the dataset.

\section{Conflict of interest}

The authors declare that they have no competing interests.

\section{Funding}

This project was supported by an award from the National Science Foundation, Division of Social and Economic Sciences (\#2027836).

\section{Supplementary material}

The data are publicly available at OpenICPSR: https://doi.org/10.3886/E130422V2.

The questionnaires are available at figshare: https://doi.org/10.6084/m9.figshare.14792058.

\section{How to cite}

Wagner AL, Rajamoorthy Y, Taib NM. Impact of economic disruptions and disease experiences on COVID-19 vaccination uptake in Asia: A study in Malaysia. Narra $J$ 2021; 1(2): e42. http://doi.org/10.52225/narraj.v1i2.42. 


\section{References}

1. Harapan H, Itoh N, Yufika A, et al. Coronavirus disease 2019 (COVID-19): A literature review. J Infect Public Health 2020;13:667-673.

2. Fahriani M, Anwar S, Yufika A, Bakhtiar B, et al. Disruption of childhood vaccination during the COVID-19 pandemic in Indonesia. Narra J 2021;1(1): e7.

3. Worldometer. COVID Live Update 2021. https://www.worldometers.info/coronavirus/\#countries (Accessed: 22 July 2021).

4. U.S. Department of State (OSAC). Health Alert: Malaysia, movement control order extensed 2021. https://www.osac.gov/Content/Report/c05f0397-e5c1-4989-a88b-1ba9ea39956e (Accessed 27 July 2021).

5. The World Bank. Emerging economic growth trends in Malaysia 2021. https://www.worldbank.org/en/news/pressrelease/2021/06/23/emerging-economic-growth-trends-in-malaysia-threatened-by-resurging-pandemic-sayslatest-world-bank-economic-monitor (Accessed 27 July 2021).

6. Mathieu E, Ritchie H, Ortiz-Ospina E, et al. A global database of COVID-19 vaccinations. Nat Hum Behav 2021;5: 947-953.

7. Izrael D, Hoaglin DC, Battaglia MP. A SAS Macro for balancing a weighted sample. Stat Data Anal 2000. https://support.sas.com/resources/papers/proceedings/proceedings/sugi25/25/st/25p258.pdf (Accessed: 16 June 2021).

8. Hotez PJ, Bottazzi ME. Developing a low-cost and accessible covid-19 vaccine for global health. PLoS Negl Trop Dis 2020; 14(7): e0008548.

9. Dubé E, MacDonald NE. How can a global pandemic affect vaccine hesitancy? Expert Rev Vaccines 2020; 19:899-901.

10. Peretti-Watel P, Verger P, Raude J, et al. Dramatic change in public attitudes towards vaccination during the 2009 influenza $A(H 1 N 1)$ pandemic in France. Eurosurveillance 2013; 18:1-8.

11. Ferrante G, Baldissera S, Moghadam PF, et al. Surveillance of perceptions, knowledge, attitudes and behaviors of the Italian adult population (18-69 years) during the 2009-2010 A/H1N1 influenza pandemic. Eur J Epidemiol 2011; 26:211-219.

12. Pool LR, Burgard SA, Needham BL, et al. Association of a negative wealth shock with all-cause mortality in middleaged and older adults in the United States. JAMA 2018; 319:1341-1350. 